\title{
PCR-based genotyping assays to detect germline $A P C$ variant associated with hereditary gastrointestinal polyposis in Jack Russell terriers
}

Kyoko Yoshizaki ${ }^{1}$, Akihiro Hirata ${ }^{1 *}$ (D) Hiroyuki Matsushita ${ }^{1}$, Naohito Nishii ${ }^{2}$, Mifumi Kawabe ${ }^{3}$, Takashi Mori ${ }^{4,5}$ and Hiroki Sakai ${ }^{1,5}$

\begin{abstract}
Background: The prevalence of gastrointestinal (Gl) neoplastic polyps in Jack Russell terriers (JRTs) has increased in Japan since the late 2000s. Recently, we demonstrated that JRTs with Gl polyps harbor identical germline variant in the APC gene (c.[462_463delinsT]]) in the heterozygous state. Thus, this disease is an autosomal dominant hereditary disorder. Although the affected JRTs have distinct features, such as the development of multiple Gl polyps and an early age of disease onset, genetic testing is indispensable for a definitive diagnosis. Here, polymerase chain reaction (PCR)-based assays capable of detecting germline APC variant were designed and validated using synthetic wild-type and mutant DNAs and genomic DNAs from carrier and non-carrier dogs.

Result: First, the PCR-restriction fragment length polymorphism (PCR-RFLP) assay was developed by taking advantage of the germline APC variant creating a new restriction site for Msel. In the PCR-RFLP assay, the 156-bp region containing the variant site was amplified by PCR and subsequently digested with Msel, yielding diagnostic 51 and $58 \mathrm{bp}$ fragments from the mutant allele and allowing determination of the APC genotypes. It was possible to determine the genotypes using genomic DNA extracted from the peripheral blood, buccal swab, or formalinfixed paraffin-embedded tissue. Next, a TaqMan duplex real-time PCR assay was developed, where a 78-bp region flanking the variant was amplified in the presence of wild-type allele- and mutant allele-specific fluorescent probes. Using blood-derived DNA, altogether 40 cycles of PCR amplification determined the APC genotypes of all examined samples by measuring the fluorescence intensities. Importantly, false-positive and false-negative errors were never detected in both assays.
\end{abstract}

Conclusion: In this study, we developed highly reliable genetic tests for hereditary Gl polyposis in JRTs, providing accurate assessment of the presence of the causative germline APC variant. The genotyping assays could contribute to the diagnosis and prevention of hereditary Gl polyposis in dogs.

Keywords: Hereditary gastrointestinal polyposis, Jack Russell terrier, Genetic testing, Diagnosis

\footnotetext{
* Correspondence: akatsuki@gifu-u.ac.jp

'Laboratory of Veterinary Pathology, Joint Department of Veterinary

Medicine, Faculty of Applied Biological Sciences, Gifu University, 1-1

Yanagido, Gifu 501-1193, Japan

Full list of author information is available at the end of the article
}

(c) The Author(s). 2021 Open Access This article is licensed under a Creative Commons Attribution 4.0 International License, which permits use, sharing, adaptation, distribution and reproduction in any medium or format, as long as you give appropriate credit to the original author(s) and the source, provide a link to the Creative Commons licence, and indicate if changes were made. The images or other third party material in this article are included in the article's Creative Commons licence, unless indicated otherwise in a credit line to the material. If material is not included in the article's Creative Commons licence and your intended use is not permitted by statutory regulation or exceeds the permitted use, you will need to obtain permission directly from the copyright holder. To view a copy of this licence, visit http://creativecommons.org/licenses/by/4.0/. The Creative Commons Public Domain Dedication waiver (http://creativecommons.org/publicdomain/zero/1.0/) applies to the data made available in this article, unless otherwise stated in a credit line to the data. 


\section{Background}

Recent advances in clinical veterinary medicine and molecular genetics, including availability of the complete canine genome sequence [1], have led to the discovery of canine and feline hereditary disorders [2-4]. The cases of gastrointestinal (GI) neoplastic polyps in Jack Russell terriers (JRTs) have increased in Japan since the late 2000s, with the suspicion of it being a novel hereditary disorder [5]. Recently, we demonstrated that JRTs with GI polyps harbor identical germline variant in the APC gene, c.[462_ 463delinsTT] (OMIA ID: 001916-9615), in the heterozygous state. Thus, this is an autosomal dominant hereditary disorder [6]. The solitary and multiple polyps were found in either one or both the stomach and colorectum, with a predilection for the gastric antrum and rectum, in the affected dogs, and most of the GI lesions were histopathologically diagnosed as adenomas or adenocarcinomas [6]. This cancer-prone disease could possibly be a canine counterpart of attenuated familial adenomatous polyposis (FAP) in humans [7].

The following features could provide clinical veterinarians with indications to diagnose hereditary GI polyposis in JRTs: (1) multiple polyps in the stomach and/or colorectum, (2) early onset of GI polyposis, and (3) repeated recurrence [6]. However, as observed in a recent study, this hereditary disease can present as a solitary GI polyp [6], with the lesion distribution similar to those of sporadic GI cancers [6, 8-10]. Although onset at a young age is a distinctive feature, initial GI lesions can arise at a wide range of ages, even after 10 years in JRTs with germline $A P C$ variant [6]. These findings indicate the necessity of genetic testing for definitive diagnosis of hereditary GI polyposis. Furthermore, JRTs with hereditary GI cancers had a longer survival time than sporadic cases but were at a higher risk for disease recurrence [6], emphasizing the need for differential diagnosis for formulating the treatment and follow-up.

Recently, genetic testing for hereditary disorders is well-established for the diagnosis of affected animals and the prediction of future risks for breed-specific diseases in several breeds [2-4]. Since hereditary GI polyposis is an adult-onset disease [6], future risk assessment is important for early detection of the onset. Furthermore, genetic testing is indispensable to prevent the spread of canine hereditary disorders $[2,3,11]$. Hereditary GI polyposis is spreading among JRTs in Japan since the 2000s, and thus, excluding the carriers of the pathogenic variant from the breeding population is necessary as early as possible.

In a recent study, we discovered a previously unknown disease-causing variant in the $A P C$ gene using PCRdirect sequencing [6]. Once the disease-causing variant is identified, other PCR-based genetic testing methods such as PCR-restriction fragment length polymorphism
(PCR-RFLP) and TaqMan real-time PCR assays can be designed, enabling rapid detection of the target variant in any standard laboratory. These assays are available for the detection of single-base changes, such as point mutations and single nucleotide polymorphisms (SNPs), and used as genotyping assays for canine hereditary diseases [12-17].

In a recent study of hereditary GI polyposis in JRTs, we developed PCR-RFLP and TaqMan duplex real-time PCR assays to investigate the molecular mechanism underlying tumor development [6]. In particular, using these assays, somatic loss of the wild-type $A P C$ allele was successfully detected in the GI tumors of JRTs with heterozygous germline $A P C$ variant [6]. These assays would also be applicable to genotyping assays for hereditary GI polyposis, but further validation is required. In this study, we showed that the PCR-RFLP and TaqMan duplex real-time PCR assays were capable of accurately determining the germline $A P C$ variant status of carrier and non-carrier dogs without any false-positive or falsenegative errors.

\section{Results \\ APC variant status of the samples}

In this study, genomic DNA samples with heterozygous germline $A P C$ variant (c.[462_463delinsTT]) were obtained from JRTs with hereditary GI polyposis. These cases were diagnosed as hereditary GI polyposis based on the detection of $A P C$ variant, and clinical and pathological characteristic findings in our previous study [6]. Samples without $A P C$ variant were obtained from JRTs with other diseases or laboratory beagles. Genomic DNA samples were extracted from the peripheral blood, buccal swab, or formalin-fixed paraffin-embedded (FFPE) tissue.

First, the germline $A P C$ variant status of all samples used in this study was validated by PCR-direct sequencing. Representative results of PCR-direct sequencing were shown in Fig. 1a. Heterozygous deletion-insertion variant involving two consecutive nucleotides, c.[462 463delinsTT], which spaned codons 154 and 155 of the canine $A P C$ gene, were detected in all the carrier JRTs, while all non-carrier JRTs and laboratory beagles were homozyous for the wild-type allele.

\section{PCR-RFLP assay}

PCR-RFLP assay was designed by taking advantage of the germline $A P C$ variant creating a new restriction site for MseI (Fig. 1b). First, the optimal time for enzyme digestion was examined. PCR products amplified from blood-derived DNAs of a carrier and a non-carrier, along with synthetic wild-type and mutant DNAs were digested for $1,2,4,8,12$, and $24 \mathrm{~h}$. The digested fragments of the expected sizes were obtained from each 


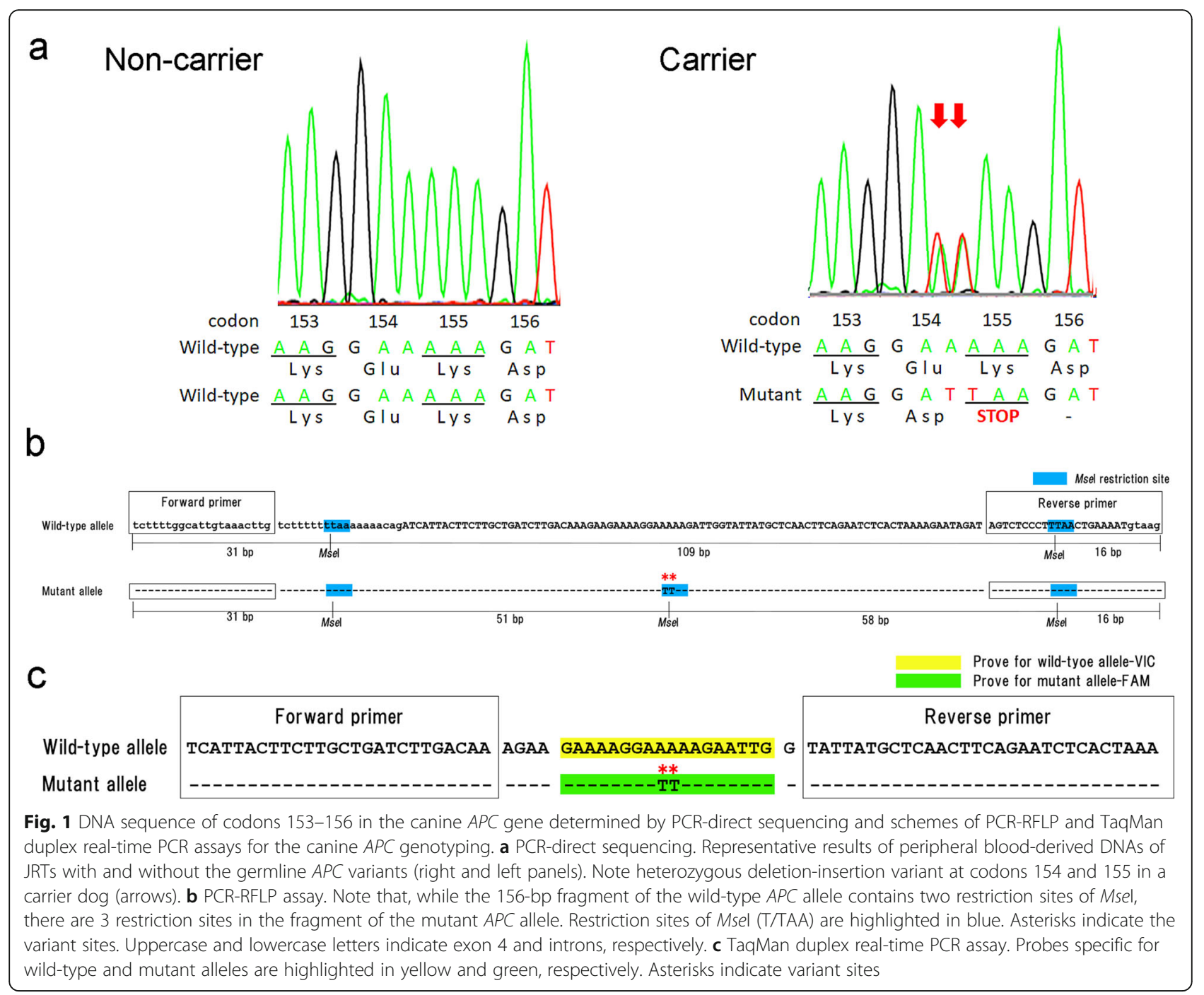

sample after $1 \mathrm{~h}$ of digestion (Supplementary Fig. 1), and the shortest digestion time was applied to the subsequent analyses. In addition, consistent with the low star activity of MseI [18], nonspecific digestion was not detected even after $24 \mathrm{~h}$ of digestion.

The initial PCR produced a single amplicon of $156 \mathrm{bp}$ from all DNA samples, irrespective of the source of the DNA template (data not shown), and subsequent enzymatic digestion yielded distinct fragment patterns, depending on the $A P C$ genotype. The amplicons from synthetic wild-type and mutant DNAs were cleaved into three fragments of 16, 31, and $109 \mathrm{bp}$, and four fragments of 16, 31, 51, and $58 \mathrm{bp}$, respectively (Fig. 2a-c and Supplementary Fig. 1). When analyzing the bloodderived DNA, PCR products from five non-carrier JRTs were cleaved into three fragments and those from 11 carrier JRTs into five fragments, including both wildtype allele-derived $109 \mathrm{bp}$ and mutant allele-derived 51 and $58 \mathrm{bp}$ fragments (Fig. 2a). The same fragmentation patterns were observed in the analyses of the buccal swabs of six carrier JRTs and five non-carrier beagles (Fig. 2b) and FFPE samples of ten carrier and five noncarrier JRTs (Fig. 2c), showing the viability of the assay using other DNA sources.

All digested PCR products were also analyzed by microchip capillary electrophoresis. An electropherogram with different peak patterns was obtained for each genotype. When the synthetic DNAs were analyzed, two peaks at 31 and $109 \mathrm{bp}$ and three peaks at 31, 51, and $58 \mathrm{bp}$ were observed for wild-type and mutant DNA, respectively (Fig. 2d). Representative results of the analysis using genomic DNAs extracted from other sources were shown in Fig. 2e-g. For non-carrier dogs, the peak pattern was the same as that for synthetic wild-type DNA (Fig. 2e-g, left panels). For carrier JRTs, a combined pattern of the wild-type and mutant DNAs was observed, with five peaks at $31,51,58$, and $109 \mathrm{bp}$ (Fig. 2e-g, right panels). Genotype-specific patterns were observed for all samples obtained from blood 


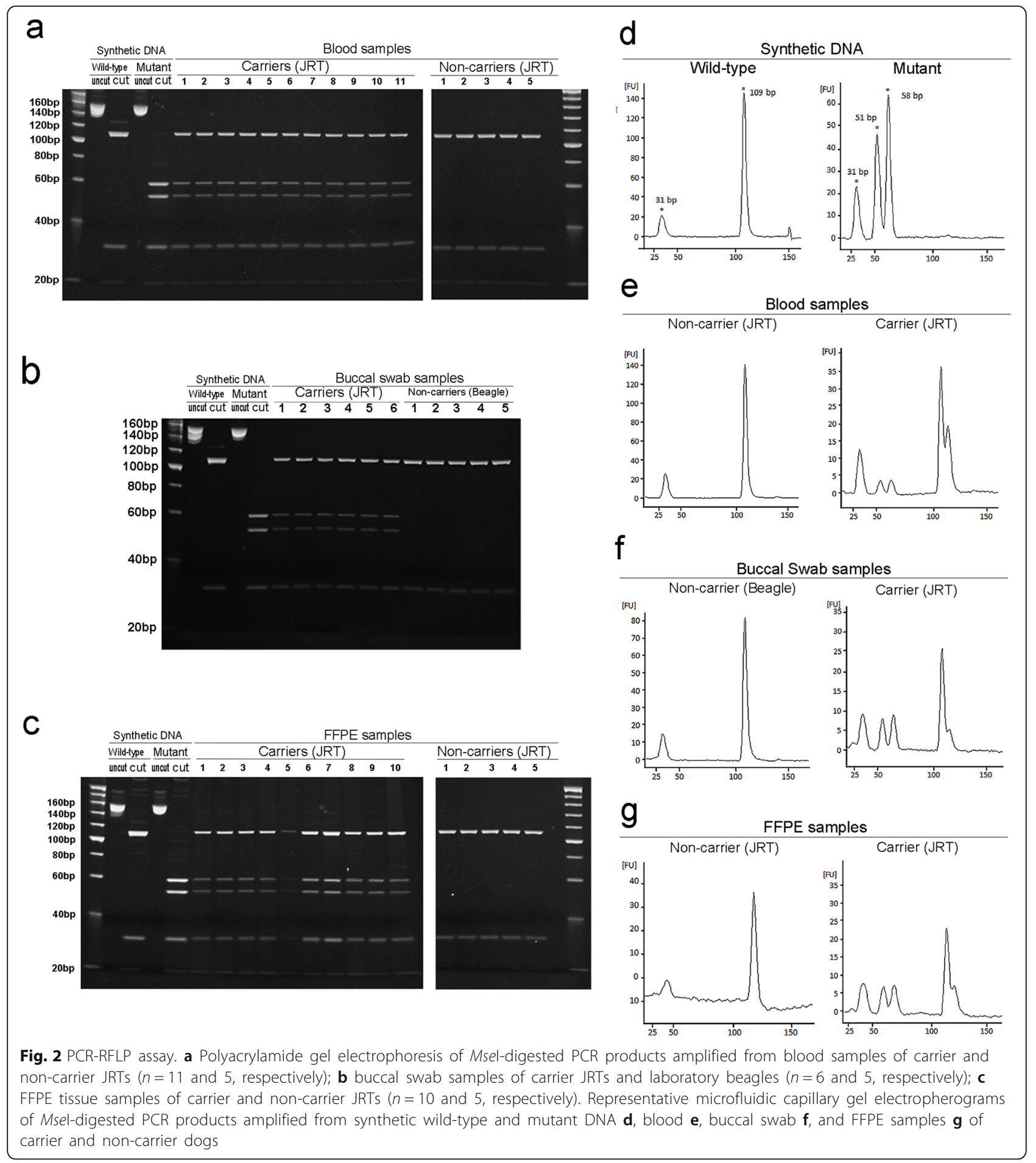

( $n=5$ and 11 for non-carrier and carrier dogs), buccal swab ( $\mathrm{n}=5$ and 6$)$, and FFPE tissues ( $\mathrm{n}=5$ and 10).

\section{TaqMan duplex real-time PCR assay}

The real-time PCR assay with TaqMan probes determined the genotypes of all samples. When the synthetic wild-type and mutant DNAs were analyzed, an exponential increase in fluorescence intensity of either VIC or FAM was observed without nonspecific allelic amplification (Fig. 3a and b, top panels). Consistently, when blood-derived DNA samples of 5 non-carrier JRTs were analyzed, only VIC fluorescence intensity increased without detection of FAM fluorescence, even after 40 cycles of amplification (Fig. 3a and b, middle and bottom 

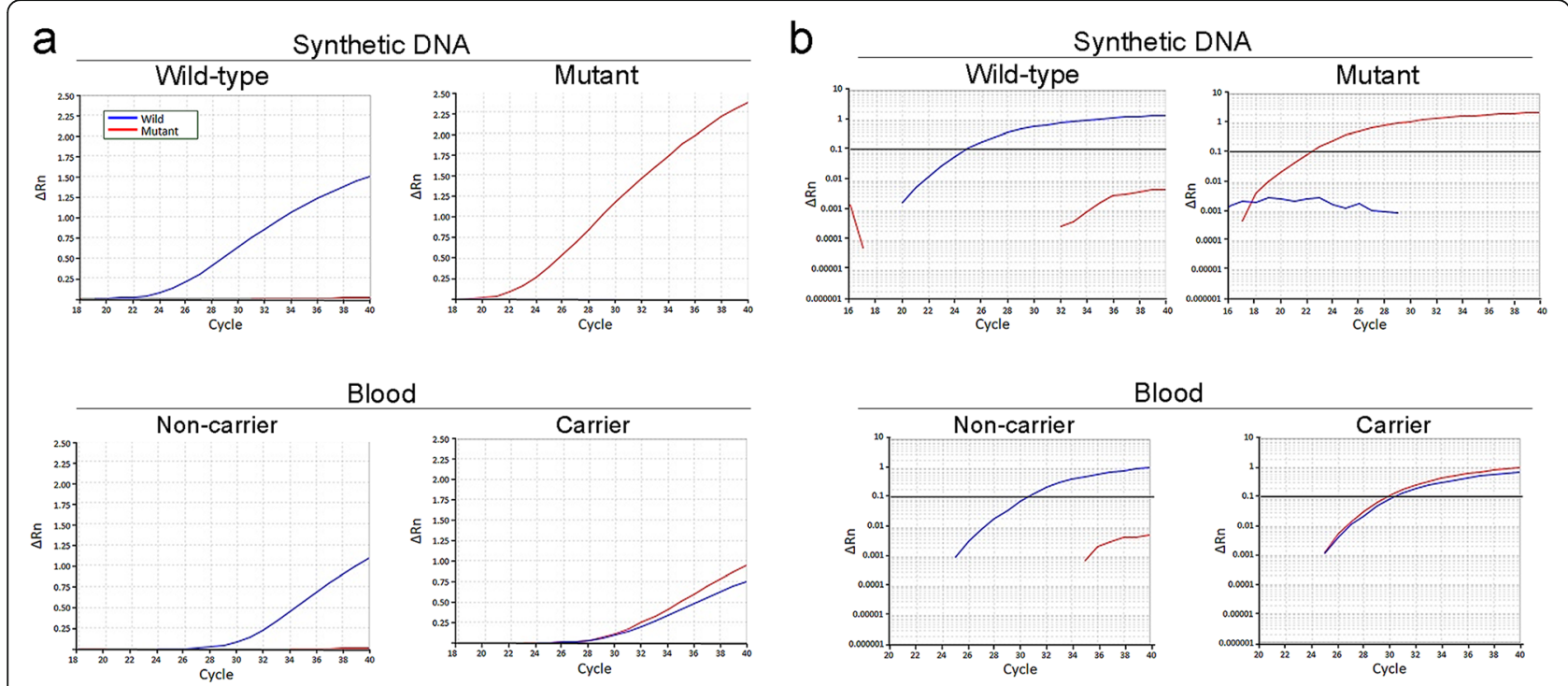

Blood
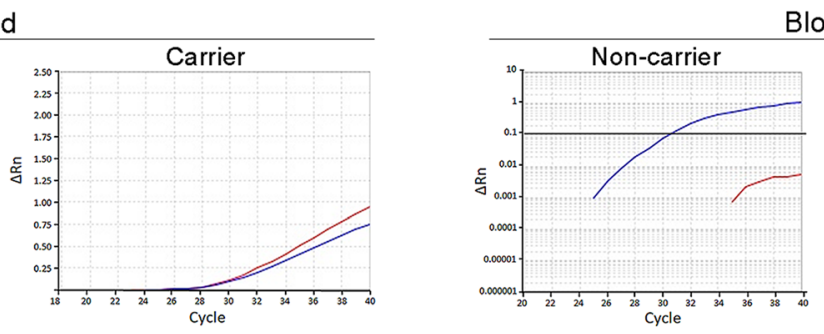

Blood
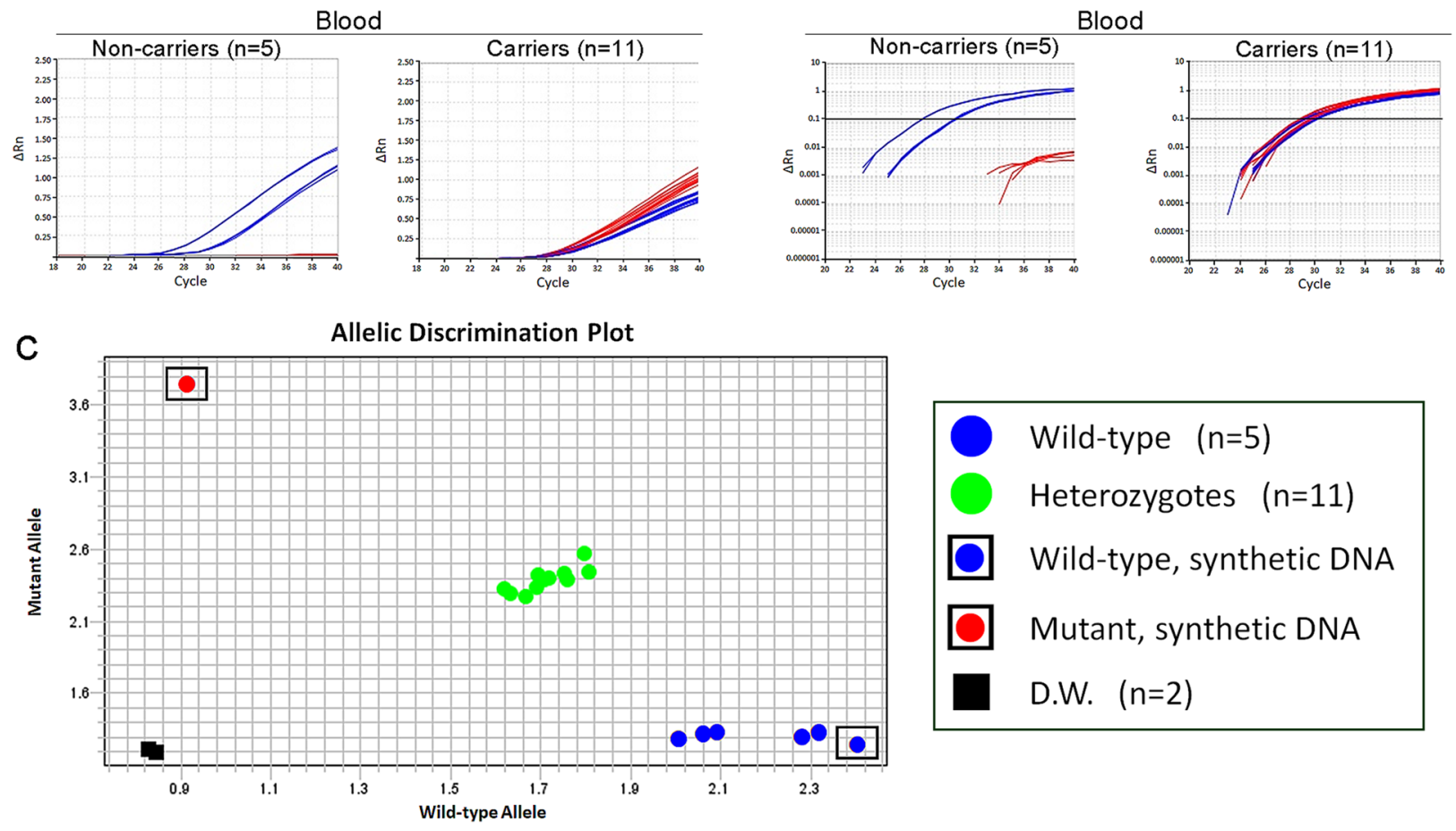

Heterozygotes ( $n=11)$

Wild-type, synthetic DNA

Mutant, synthetic DNA

D.W. $(\mathrm{n}=2)$

Fig. 3 TaqMan duplex real-time PCR assay. a, b Amplification plots of wild-type (blue curve) and mutant (red curve) APC gene copies on synthetic wild-type and mutant DNAs (upper panels) and blood-derived DNAs of carrier or non-carrier JRTs (middle and lower panels).

Amplification was plotted as fluorescence intensity $(\Delta R n$ value) against cycle numbers and shown on linear (a) and log (b) scales. The middle panels show representative results of individual cases of carrier or non-carrier dogs and the lower panels summarize the results of all examined cases ( $n=11$ and 5 for carrier and non-carrier JRTs, respectively). c Allelic discrimination plot based on the signal intensity ratio of FAM and VIC at the end points of PCR amplification. Synthetic wild-type and mutant DNAs are located at bottom right and top left corners, respectively, and distilled water used as negative control is at bottom left corner. Non-carrier JRTs are clustered together with the synthetic wild-type DNA at bottom right corner. Carrier JRTs are located near the diagonal line forming a distinct cluster

panels). When the DNA samples of 11 JRTs with the germline $A P C$ variant were examined, both FAM and VIC fluorescence intensities increased simultaneously and exceeded the baseline level at around 30 cycles (Fig. 3a and $\mathrm{b}$, middle and bottom panels).
Figure 3c shows the allelic discrimination plot constructed based on the signal intensity ratio of FAM and VIC at the end points of PCR amplification. The examined samples were divided into the following three clusters, predicting their genotypes with 100\% accuracy: (1) 
wild-type cluster consisting of synthetic wild-type DNA and five non-carrier dogs, (2) heterozygote cluster of 11 carrier dogs, and (3) the mutant synthetic DNA.

\section{Discussion}

In this study, we developed highly reliable genetic tests for hereditary GI polyposis in JRTs, providing accurate assessment of the presence of the causative germline $A P C$ variant, c.[462_463delinsTT] [6]. Importantly, falsepositive and false-negative errors were never detected in both PCR-RFLP and TaqMan real-time PCR assays, demonstrating the high specificity and sensitivity of the established assays. While PCR-RFLP and TaqMan PCR assays are capable of detecting even a single-base difference, the target $A P C$ variant is a deletion-insertion variant involving two consecutive nucleotides [6], providing substantial advantage to enhance the specificities of the established assays.

Although the PCR-RFLP assay is one of the most common methods for genotyping, a lack of suitable restriction enzymes hinders its application in some cases. In this study, we successfully developed the PCR-RFLP assay for hereditary GI polyposis by taking advantage of the causative germline $A P C$ variant creating a new restriction enzyme site for MseI. In the PCR-RFLP assay, $M s e$ I digestion yielded diagnostic fragments of 51 and $58 \mathrm{bp}$ from the mutant $A P C$ allele and differentiated carrier and non-carrier dogs. In this assay, the PCR amplicon contained two restriction sites of MseI besides the variant site; therefore, the 156-bp band disappeared after the digestion regardless of the genotypes, contributing to the prevention of false negative errors by incomplete digestion. Furthermore, the entire process of this assay can be completed within half a day using an ordinary thermal cycler and electrophoresis apparatus, enabling rapid diagnosis in any standard laboratory. In addition, by using the buccal swab as test materials, determination of the genotypes is possible in a less invasive manner. Moreover, when dogs are suspected to have a hereditary disease on histopathological examination of their GI lesions, it is possible to determine their $A P C$ genotype from FFPE samples without the need for additional blood or swab samples. This approach is also applicable to retrospective studies using archival FFPE samples.

TaqMan duplex real-time PCR assay requires dedicated equipment capable of measuring multiple fluorescences in real time, but this assay enables high-throughput genotyping. Therefore, it is suitable for large-scale molecular epidemiological studies. Another advantage of this assay is determination of genotypes in a single PCR without any additional post-amplification manipulations, thus minimizing the risk of human errors.

The genetic tests developed in this study would provide significant benefits in small animal practice. Clinical veterinarians need to differentiate between hereditary and sporadic GI cancers in dogs for the following reasons. First, JRTs affected with the hereditary disease are much more likely than sporadic cases to have multiple cancers [6]. Second, in the case of the hereditary GI polyposis, the affected dogs can be expected to have a longer survival time than sporadic cases although they have an increased lifelong risk of disease recurrence [6]. The genetic testing enables the differential diagnosis between hereditary and sporadic GI cancers. In addition, JRTs with chronic GI symptoms such as vomiting and bloody stool can be candidates for genetic testing [6] Considering that endoscopic examination requires general anesthesia in dogs, genetic testing could be an option to predict the occurrence of GI lesions in JRTs. The positive test results strongly support the need for further examinations such as endoscopy. Furthermore, genetic testing would be useful for the assessment of future risk for hereditary GI polyps. Many commercial laboratories offer genetic tests for canine and feline hereditary diseases [4], available to pet owners and veterinarians for assessment of lifelong risk. Hereditary GI polyposis is an adult-onset disease, and initial GI lesions can arise at variable ages, reportedly between 2 to over 10 years [6]. Therefore, knowing the lifelong risk is necessary for early detection and treatment.

Genetic testing is indispensable for preventing the spread of hereditary diseases in dogs $[2,3,11]$. In adultonset diseases, there is a risk of the carriers of pathogenic variant being unintentionally used for breeding before the disease onset. If a popular sire, such as a dog show champion, is a variant carrier, causative variant can spread rapidly within the breed due to their extensive use for breeding [2]. Our previous retrospective study revealed that the incidence of GI polyposis in JRTs increased since the late 2000s, and that all the affected dogs were born during the first decade of the 2000s [6]. The spread of hereditary GI polyposis among JRTs in Japan might be due to the popular sire effect during this period. Proper genetic screening of sires and dams before breeding would prevent the transmission of germline $A P C$ variant to future generations. This approach would substantially reduce the future incidence and eventually eradicate this hereditary disease in the future. Therefore, genetic screening should preferably become a routine for animal breeding $[2,4]$.

The genotyping assays established in this study would certainly facilitate large-scale epidemiological studies. There are no reports of JRTs with hereditary GI polyposis in other countries, except Japan; thus, the germline $A P C$ variant are possibly prevalent only among JRTs in Japan. However, when examining the pedigree certificates of the JRTs affected by hereditary GI polyposis, some ancestor dogs were introduced from Australia 
(unpublished data), and thus there is a possibility of the presence of JRTs with the germline $A P C$ variant in other countries. Furthermore, the prevalence of germline $A P C$ variant in JRTs in Japan remains to be investigated. Further studies are needed to clarify the prevalence of germline $A P C$ variant in JRTs in Japan and other countries. Moreover, in future epidemiological studies of healthy JRTs, the carrier dogs could be identified before disease onset, indicating the usefulness of genetic testing for future risk assessment.

\section{Conclusions}

In this study, we established reliable genetic tests for hereditary GI polyposis in JRTs, enabling definitive diagnosis, lifelong risk assessment of this novel disease, and prevention of transmission of germline $A P C$ variant to future generations. Since dogs affected by this hereditary disease developed multifocal and recurrent GI polyps, development of non-surgical treatment options is desirable. These assays could be incorporated into small veterinary practices in the near future, laying groundwork for the establishment of effective therapy for hereditary GI polyposis.

\section{Materials and methods \\ Samples and DNA extraction Blood samples}

Peripheral blood was collected from 11 JRTs with hereditary GI polyposis. Blood samples taken from five JRTs with other diseases (portosystemic shunt, chronic cholecystitis, lymphoma, mast cell tumor and liver tumor) for clinical blood testing at the Gifu University Teaching Animal Hospital served as non-carriers. Genomic DNA was extracted from EDTA-anticoagulated blood samples using the Wizard Genomic DNA Purification Kit (Promega, Madison, WI) or the DNeasy Blood \& Tissue Kit (QIAGEN, Venlo, Netherlands) according to the manufacturer's instructions.

\section{Buccal swab samples}

Buccal swabs were collected from six JRTs with hereditary GI polyposis and five laboratory beagles using cotton-tipped swabs or 4 N6 FLOQ Swabs ${ }^{\mathrm{TM}}$ (COPAN Flock Technologies, Brescia, Italy) and stored at $20^{\circ} \mathrm{C}$ until use. Genomic DNA was extracted using the DNeasy Blood \& Tissue Kit (QIAGEN). Briefly, the head of the swab was incubated in a mixture containing $20 \mu \mathrm{L}$ proteinase $\mathrm{K}$ solution $(>600 \mathrm{mAU} / \mathrm{mL})$, $400 \mu \mathrm{L}$ Buffer $\mathrm{A}$, and $400 \mu \mathrm{L}$ PBS at $56^{\circ} \mathrm{C}$ for $10 \mathrm{~min}$, and the lysate was purified according to the manufacturer's instructions.

\section{FFPE tissue samples}

Archival FFPE tissue specimens stored in the Laboratory of Veterinary Pathology at the Gifu University were used. Genomic DNA was extracted from non-neoplastic tissues on FFPE specimens of 15 JRTs, including 10 dogs with hereditary GI polyposis and five with other diseases (chronic gingivitis, fibrous follicular harmartoma, lipoma, fibrous gingival hyperplasia and cystic dilatation of mammary duct), using the QIAamp DNA FFPE Tissue Kit (QIAGEN).

\section{Synthetic DNA}

Obtaining DNA samples homozygous for the mutant $A P C$ alleles from dogs is impossible because of embryonic lethality in animals with germline homozygous $A P C$ variants [19]. To prepare control DNA templates homozygous for wild-type or mutant $A P C$ alleles, 309-bp DNA fragments were synthesized based on the predicted sequences of the canine $A P C$ gene (GenBank accession No. NC_006585.3 and XM_014111995.2) (Takara Bio, Shiga, Japan) and cloned into T-Vector pMD20 (Takara Bio). The synthetic DNA fragments contained entire exon 4 (109 bp) with the most proximal $100 \mathrm{bp}$ of both upstream and downstream introns. In the mutant type, in accordance with the germline $A P C$ variant in the affected JRTs (c.[462_463delinsTT]) [6], adenosine bases at nucleotides 462 and 463 were replaced with thymine bases.

\section{PCR-direct sequencing}

To validate the $A P C$ variant status of each sample, PCRdirect sequencing was conducted as previously reported [6]. PCR was performed with TaKaRa EX Taq Hot Start Version (Takara Bio) to amplify a 385-bp fragment containing exon 4 of the canine $A P C$ gene from the blood and swab samples and a 156-bp fragment containing nucleotides 462 and 463 in exon 4 from the FFPE samples. The primers used are listed in Table 1. After electrophoresis on the $3.0 \%$ agarose gel, PCR products were extracted using the QIAquick Gel Extraction Kit (QIAG EN). The purified PCR products were subjected to sequencing analysis using an ABI Prism 3500 Genetic Analyzer (Applied Biosystems, Foster City, CA) with the Big Dye Terminator v3.1 Cycle sequencing Kit (Thermo Fisher Scientific, Waltham, MA).

\section{Protocol for PCR-based diagnostic assays PCR-RFLP assay}

DNA fragments of $156 \mathrm{bp}$, containing the variant sites at nucleotides 462 and 463 of the canine $A P C$ gene, were amplified by PCR using Takara EX Taq Hot Start Version (Takara Bio). PCR reaction mixtures $(20 \mu \mathrm{L})$ contained $2 \mu \mathrm{L}$ of $10 \times$ Ex Taq buffer $\left(\mathrm{Mg}^{2+}\right.$ plus $), 2.5 \mathrm{mM}$ of each dNTP, $0.15 \mu \mathrm{M}$ of each primer, and $0.75 \mathrm{U}$ of 
Table 1 Primers and probes used for PCR-based assays for detection of the germline APC variant

\begin{tabular}{|c|c|c|c|c|c|}
\hline & & & \multicolumn{2}{|l|}{ Sequence } & Product size (bp) \\
\hline \multicolumn{6}{|c|}{ Primers used for PCR-direct sequencing } \\
\hline \multirow[t]{2}{*}{ Primers } & sense & $5^{\prime-}$ & AGTCCCACCTTCAAAAATCC & $-3^{\prime}$ & 385 \\
\hline & antisense & $5^{\prime-}$ & AACTAAAAATGCAATTATCTTGAATG & $-3^{\prime}$ & \\
\hline \multicolumn{6}{|c|}{ Primers used for PCR-RFLP and PCR-directsequencing of FFPE samples } \\
\hline \multirow[t]{2}{*}{ Primers } & sense & $5^{\prime}-$ & TCTTTTGGCATTGTGTAAACTTG & $-3^{\prime}$ & 156 \\
\hline & antisense & $5^{\prime-}$ & CTTACATTTCAGTTAAAGGGAGACT & $-3^{\prime}$ & \\
\hline \multicolumn{6}{|c|}{ Primers and probes used for Taq-Man duplex real-time PCR assay } \\
\hline \multirow[t]{2}{*}{ Primers } & sense & $5^{\prime}-$ & TTTAGTGAGATTCTGAAGTTGAGCATAATA & $-3^{\prime}$ & 78 \\
\hline & antisense & $5^{\prime}-$ & TCATTACTTCTTGCTGATCTTGACAA & $-3^{\prime}$ & \\
\hline \multicolumn{2}{|c|}{ Probe for Wild-type allele } & $5^{\prime}-$ & (VIC)- CAATCTITTCCTITTC-(MGB) & $-3^{\prime}$ & \\
\hline \multicolumn{2}{|c|}{ Probe for Mutant allele } & $5^{\prime}-$ & (FAM)-CAATCTTAATCCTTTC-(MGB) & $-3^{\prime}$ & \\
\hline
\end{tabular}

VIC 2-chloro-7'-phenyl-1,4-dichloro-6-carboxy-fluorescein, FAM 6-carboxyfluorescein, NFQ nonfluorescent quencher, MGB minor groove binder

Takara Ex Taq DNA polymerase, and $1 \mu \mathrm{L}$ of DNA template. The primers used are listed in Table 1 . The cycling conditions consisted of an initial denaturation at $94^{\circ} \mathrm{C}$ for $5 \mathrm{~min}$, followed by 35 cycles of denaturation at $94^{\circ} \mathrm{C}$ for $30 \mathrm{~s}$, annealing at $58^{\circ} \mathrm{C}$ for $30 \mathrm{~s}$, extension at $72^{\circ} \mathrm{C}$ for $30 \mathrm{~s}$, and a final extension at $72^{\circ} \mathrm{C}$ for $5 \mathrm{~min}$. Before enzymatic digestion, $4 \mu \mathrm{L}$ of the PCR products were analyzed by electrophoresis on $1.5 \%$ agarose gel. The remaining PCR products were digested with restriction enzyme MseI (RspRSII) (Takara Bio) at $60^{\circ} \mathrm{C}$ in a $20-\mu \mathrm{L}$ reaction mixture containing 10 units of $M s e \mathrm{I}, 2 \mu \mathrm{L}$ of $10 \times$ buffer, $2 \mu \mathrm{L}$ of $0.1 \%$ bovine serum albumin, and $15 \mu \mathrm{L}$ of the product. The digested products were separated by electrophoresis on $15 \%$ polyacrylamide gel (SuperSep $^{\text {tw }}$ Ace, Wako Pure Chemical Industries, Osaka, Japan). DNA bands were visualized with a UV transilluminator after staining with ethidium bromide $(0.5 \mu \mathrm{g} /$ $\mathrm{mL}$ ). The digested PCR products were also analyzed by microfluidic capillary gel electrophoresis using an Agilent 2100 bioanalyzer (Agilent Technologies, Santa Clara, CA) with an Agilent DNA 1000 kit (Agilent Technologies).

\section{TaqMan duplex real-time $P C R$ assay}

Primers were designed to amplify DNA fragments of 78 bp in size, containing the variant sites at nucleotides 462 and 463 of the canine APC gene. TaqMan probes were designed to bind specifically to the wild-type or mutant sequences (Thermo Fisher Scientific). The location and sequences of the primers and probes are shown in Fig. 1c and Table 1 . The probes were modified with 2-chloro- $7^{\prime}$ phenyl-1,4-dichloro-6-carboxy-fluorescein (VIC) or 6carboxyfluorescein (FAM) at the $5^{\prime}$ end and with a nonfluorescent quencher and minor groove binder (MGB) at the 3 ' end. Real-time PCR was carried out in a $50-\mu \mathrm{L}$ reaction mixture containing TaqMan Genotyping Master Mix (Thermo Fisher Scientific), $0.9 \mu \mathrm{M}$ of each primer,
$0.2 \mu \mathrm{M}$ of the mutant and wild-type probes, and $10 \mathrm{ng}$ of template DNA. The ABI StepOne Plus system (Applied Biosystems) was used to amplify and quantify the PCR products. The cycling conditions were $95^{\circ} \mathrm{C}$ for $10 \mathrm{~min}$, followed by 40 cycles of $95^{\circ} \mathrm{C}$ for $15 \mathrm{~s}$ and $60^{\circ} \mathrm{C}$ for $1 \mathrm{~min}$. Data analysis was conducted using the StepOne software v2.3 (Applied Biosystems).

\section{Supplementary Information}

The online version contains supplementary material available at https://doi. org/10.1186/s12917-020-02731-7

Additional file 1: Figure S1. PCR-RFLP assay conducted to determine the optimal digestion time. Acrylamide gel electrophoresis of Mseldigested PCR products amplified from synthetic wild-type and mutant DNA (A), and blood-derived DNA samples of a carrier and a non-carrier of germline $A P C$ variant (B). PCR products amplified from each sample were digested with Msel for 0, 1, 2, 4, 8, 12, and $24 \mathrm{~h}$.

\section{Abbreviations}

Gl: Gastrointestinal; JRT: Jack Russell terrier; PCR: Polymerase chain reaction; PCR-RFLP: PCR-restriction fragment length polymorphism; FAP: Familial adenomatous polyposis

\section{Acknowledgements}

The authors thank Prof. Katsuya Kitoh (Gifu University) for providing samples from laboratory beagles and Dr. Yosuke Uematsu and Tomohiro Yamaguchi (Canine-Lab. Inc.) for their helpful advice.

\section{Authors' contributions}

$\mathrm{AH}$ designed the current study. NN, MK, and TM collected the samples at veterinary teaching hospital and $\mathrm{KY}, \mathrm{AH}, \mathrm{HM}$, and $\mathrm{HS}$ at laboratory of veterinary pathology at Gifu University. $\mathrm{KY}$ and AH designed PCR-based assays. $\mathrm{KY}, \mathrm{AH}$, and $\mathrm{HM}$ collected and interpreted the data. $\mathrm{KY}$ and $\mathrm{AH}$ drafted the manuscript. All authors have read and approved the final manuscript.

\section{Funding}

This work was supported by JSPS KAKENHI Grant Number 18 K05969. The funding body had no role in the design of the study and collection, analysis, and interpretation of data and in writing the manuscript.

\section{Availability of data and materials}

The datasets used and/or analysed during the current study are available from the corresponding author on reasonable request. 


\section{Ethics approval and consent to participate}

Samples were collected with informed owner consent and with approval of the Committee for Animal Research and Welfare of Gifu University (approval number: 2019-156).

\section{Consent for publication}

Not Applicable.

\section{Competing interests}

The authors declared that they have no competing interests.

\section{Author details}

'Laboratory of Veterinary Pathology, Joint Department of Veterinary Medicine, Faculty of Applied Biological Sciences, Gifu University, 1-1 Yanagido, Gifu 501-1193, Japan. ${ }^{2}$ Laboratory of Veterinary Internal Medicine, Joint Department of Veterinary Medicine, Faculty of Applied Biological Sciences, Gifu University, 1-1 Yanagido, Gifu 501-1193, Japan. ${ }^{3}$ Laboratory of Veterinary Clinical Radiology, Joint Department of Veterinary Medicine, Faculty of Applied Biological Sciences, Gifu University, 1-1 Yanagido, Gifu 501-1193, Japan. ${ }^{4}$ Laboratory of Veterinary Clinical Oncology, Joint Department of Veterinary Medicine, Faculty of Applied Biological Sciences, Gifu University, 1-1 Yanagido, Gifu 501-1193, Japan. ${ }^{5}$ Center for Highly Advanced Integration of Nano and Life Sciences, Gifu University (G-CHAIN), 1-1 Yanagido, Gifu 501-1193, Japan.

Received: 7 October 2020 Accepted: 22 December 2020

Published online: 18 January 2021

\section{References}

1. Lindblad-Toh K, Wade CM, Mikkelsen TS, Karlsson EK, Jaffe DB, Kamal M, Clamp M, Chang JL, Kulbokas EJ 3rd, Zody MC, et al. Genome sequence, comparative analysis and haplotype structure of the domestic dog. Nature. 2005;438(7069):803-19

2. Giger U, Sargan DR, McNiel EA. Breed-specific Hereditary Diseases and Genetic Screening. In: Ostrander EA, Giger U, Lindblad-Toh K, editors. The Dog and Its Genome. New York: Cold Spring Harbor Laboratory Press; 2006. p. 249-89.

3. Gough A, Thomas A, O'Neill D. Introduction. In: Alex Gough AT, O'Neill D, editors. Breed predispositions to disease in dogs and cats. 3 edn. Hoboken: Wiley; 2018. p. 1-16.

4. Slutsky J, Raj K, Yuhnke S, Bell J, Fretwell N, Hedhammar A, Wade C, Giger U. A web resource on DNA tests for canine and feline hereditary diseases. Vet J. 2013;197(2):182-7.

5. Saito T, Nibe K, Chambers JK, Uneyama M, Nakashima K, Ohno K, Tsujimoto H, Uchida K, Nakayama H. A histopathological study on spontaneous gastrointestinal epithelial tumors in dogs. J Toxicol Pathol. 2020;33(2):10513.

6. Yoshizaki K, Hirata A, Nishii N, Kawabe M, Goto M, Mori T, Sakai H. Familial Adenomatous Polyposis in Dogs: Hereditary Gastrointestinal Polyposis in Jack Russell Terriers with Germline APC Mutations. Carcinogenesis. 2020. https://doi.org/10.1093/carcin/bgaa045.

7. Giardiello FM, Burt RW, Järvinin HJ, Offerhaus GJ. Familial adenomatous polyposis. In: Bosman FT, Carneiro F, Hruban RH, Theise ND, editors. WHO Classification of Tumours of the Digestive System. 4th Edition edn. Lyon: World Health Organization; 2010. p. 147-51.

8. Munday John S, LCV, Matti K. Tumors of the Alimentary Tract. In: Meuten DJ editor. Tumors in Domestic Animals. 5 edn. Hoboken: Wiley; 2017. p. 499601.

9. Patnaik AK, Hurvitz Al, Johnson GF. Canine gastrointestinal neoplasms. Vet Pathol. 1977;14(6):547-55.

10. Swann HM, Holt DE. Canine gastric adenocarcinoma and leiomyosarcoma: a retrospective study of 21 cases (1986-1999) and literature review. J Am Anim Hosp Assoc. 2002;38(2):157-64.

11. Farrell LL, Schoenebeck JJ, Wiener P, Clements DN, Summers KM. The challenges of pedigree dog health: approaches to combating inherited disease. Canine Genet Epidemiol. 2015;2:3

12. Chang HS, Arai T, Yabuki A, Hossain MA, Rahman MM, Mizukami K, Yamato $\mathrm{O}$. Rapid and reliable genotyping technique for GM1 gangliosidosis in Shiba dogs by real-time polymerase chain reaction with TaqMan minor groove binder probes. J Vet Diagnostic Invest. 2010;22(2):234-7.
13. Chang HS, Kamishina H, Mizukami K, Momoi Y, Katayama M, Rahman MM, Uddin MM, Yabuki A, Kohyama M, Yamato O. Genotyping assays for the canine degenerative myelopathy-associated c.118G>A (p.E40K) mutation of the SOD1 gene using conventional and real-time PCR methods: a high prevalence in the Pembroke Welsh Corgi breed in Japan. J Vet Med Sci. 2013;75(6):795-8.

14. Kohyama M, Tada N, Mitsui H, Tomioka H, Tsutsui T, Yabuki A, Rahman MM, Kushida K, Mizukami K, Yamato O. Real-time PCR genotyping assay for canine progressive rod-cone degeneration and mutant allele frequency in Toy Poodles, Chihuahuas and Miniature Dachshunds in Japan. J Vet Med Sci. 2016:78(3):481-4.

15. Mizukami K, Chang HS, Yabuki A, Kawamichi T, Kawahara N, Hayashi D, Hossain MA, Rahman MM, Uddin MM, Yamato O. Novel rapid genotyping assays for neuronal ceroid lipofuscinosis in Border Collie dogs and high frequency of the mutant allele in Japan. J Vet Diagnostic Invest. 2011;23(6): 1131-9.

16. Mizukami K, Yabuki A, Kawamichi T, Chang HS, Rahman MM, Uddin MM, Kohyama M, Yamato O. Real-time PCR genotyping assay for canine trapped neutrophil syndrome and high frequency of the mutant allele in Border collies. Vet J. 2013:195(2):260-1.

17. Rahman MM, Yabuki A, Kohyama M, Mitani S, Mizukami K, Uddin MM, Chang HS, Kushida K, Kishimoto M, Yamabe R, et al. Real-time PCR genotyping assay for GM2 gangliosidosis variant 0 in toy poodles and the mutant allele frequency in Japan. J Vet Med Sci. 2014;76(2):295-9.

18. Wei H, Therrien C, Blanchard A, Guan S, Zhu Z. The Fidelity Index provides a systematic quantitation of star activity of DNA restriction endonucleases. Nucleic Acids Res. 2008;36(9):e50.

19. Moser AR, Shoemaker AR, Connelly CS, Clipson L, Gould KA, Luongo C, Dove WF, Siggers PH, Gardner RL. Homozygosity for the Min allele of Apc results in disruption of mouse development prior to gastrulation. Dev Dynamics. 1995;203(4):422-33.

\section{Publisher's Note}

Springer Nature remains neutral with regard to jurisdictional claims in published maps and institutional affiliations.
Ready to submit your research? Choose BMC and benefit from:

- fast, convenient online submission

- thorough peer review by experienced researchers in your field

- rapid publication on acceptance

- support for research data, including large and complex data types

- gold Open Access which fosters wider collaboration and increased citations

- maximum visibility for your research: over $100 \mathrm{M}$ website views per year

At BMC, research is always in progress.

Learn more biomedcentral.com/submissions 